\title{
Cell cycle control and environmental response by second messengers in Caulobacter crescentus
}

\author{
Chunrui $\mathrm{Xu}^{1 \dagger}{ }^{\dagger}$, Bronson R. Weston ${ }^{1 \dagger}$, John J. Tyson ${ }^{2}$ and Yang Cao ${ }^{3 *}$
}

From The Sixth International Workshop on Computational Network Biology: Modeling, Analysis, and Control (CNB-MAC 2019)

Niagara Falls, NY, USA. 07 September 2019

\author{
*Correspondence: ycao@cs.vt.edu \\ ${ }^{\dagger}$ Chunrui $\mathrm{Xu}$ and Bronson Weston \\ contributed equally to this work. \\ ${ }^{3}$ Department of Computer Science, \\ Virginia Tech, 24061 Blacksburg, VA, \\ USA \\ Full list of author information is \\ available at the end of the article
}

\begin{abstract}
Background: Second messengers, c-di-GMP and (p)ppGpp, are vital regulatory molecules in bacteria, influencing cellular processes such as biofilm formation, transcription, virulence, quorum sensing, and proliferation. While c-di-GMP and (p)ppGpp are both synthesized from GTP molecules, they play antagonistic roles in regulating the cell cycle. In C. crescentus, c-di-GMP works as a major regulator of pole morphogenesis and cell development. It inhibits cell motility and promotes S-phase entry by inhibiting the activity of the master regulator, CtrA. Intracellular (p)ppGpp accumulates under starvation, which helps bacteria to survive under stressful conditions through regulating nucleotide levels and halting proliferation. (p)ppGpp responds to nitrogen levels through RelA-SpoT homolog enzymes, detecting glutamine concentration using a nitrogen phosphotransferase system (PTS ${ }^{\mathrm{Ntr}}$ ). This work relates the guanine nucleotide-based second messenger regulatory network with the bacterial PTS ${ }^{\text {Ntr }}$ system and investigates how bacteria respond to nutrient availability.

Results: We propose a mathematical model for the dynamics of c-di-GMP and (p)ppGpp in C. crescentus and analyze how the guanine nucleotide-based second messenger system responds to certain environmental changes communicated through the PTS Ntr system. Our mathematical model consists of seven ODEs describing the dynamics of nucleotides and PTS ${ }^{\mathrm{Ntr}}$ enzymes. Our simulations are consistent with experimental observations and suggest, among other predictions, that SpoT can effectively decrease c-di-GMP levels in response to nitrogen starvation just as well as it increases (p)ppGpp levels. Thus, the activity of SpoT (or its homologues in other bacterial species) can likely influence the cell cycle by influencing both c-di-GMP and (p)ppGpp.

(Continued on next page)
\end{abstract} which permits use, sharing, adaptation, distribution and reproduction in any medium or format, as long as you give appropriate credit to the original author(s) and the source, provide a link to the Creative Commons licence, and indicate if changes were made. The images or other third party material in this article are included in the article's Creative Commons licence, unless indicated otherwise in a credit line to the material. If material is not included in the article's Creative Commons licence and your intended use is not permitted by statutory regulation or exceeds the permitted use, you will need to obtain permission directly from the copyright holder. To view a copy of this licence, visit http://creativecommons.org/licenses/by/4.0/. The Creative Commons Public Domain Dedication waiver (http://creativecommons.org/publicdomain/zero/1.0/) applies to the data made available in this article, unless otherwise stated in a credit line to the data. 
(Continued from previous page)

Conclusions: In this work, we integrate current knowledge and experimental observations from the literature to formulate a novel mathematical model. We analyze the model and demonstrate how the PTS ${ }^{\text {Ntr }}$ system influences (p)ppGpp, c-di-GMP, GMP and GTP concentrations. While this model does not consider all aspects of PTS ${ }^{\text {Ntr }}$ signaling, such as cross-talk with the carbon PTS system, here we present our first effort to develop a model of nutrient signaling in C. crescentus.

Keywords: c-di-GMP, (p)ppGpp, Caulobacter crescentus, Nitrogen starvation, Cell cycle

\section{Background}

Caulobacter crescentus is an oligotrophic, Gram-negative $\alpha$-proteobacterium, frequently found in freshwater environments. C. crescentus undergoes asymmetric cell division, yielding two distinct progeny cells (Fig. 1): a non-motile 'stalked' cell (st) immediately re-enters the cell cycle and initiates DNA replication, while a motile 'swarmer' cell (sw) explores its environment before differentiating into a stalked cell and re-entering the cell cycle [1]. The stalked cell is equipped with a holdfast to attach to solid surfaces in its environment, whereas the swarmer cell develops a flagellum to move around in search of a suitable nutrient environment. The asymmetric cell cycle affords $C$. crescentus a certain flexibility to cope with the vagaries of life in an oligotrophic, aquatic environment [2].

Since asymmetric cell division plays an essential role in survival for C. crescentus, understanding how the asymmetry is regulated provides insight into the life cycle of many

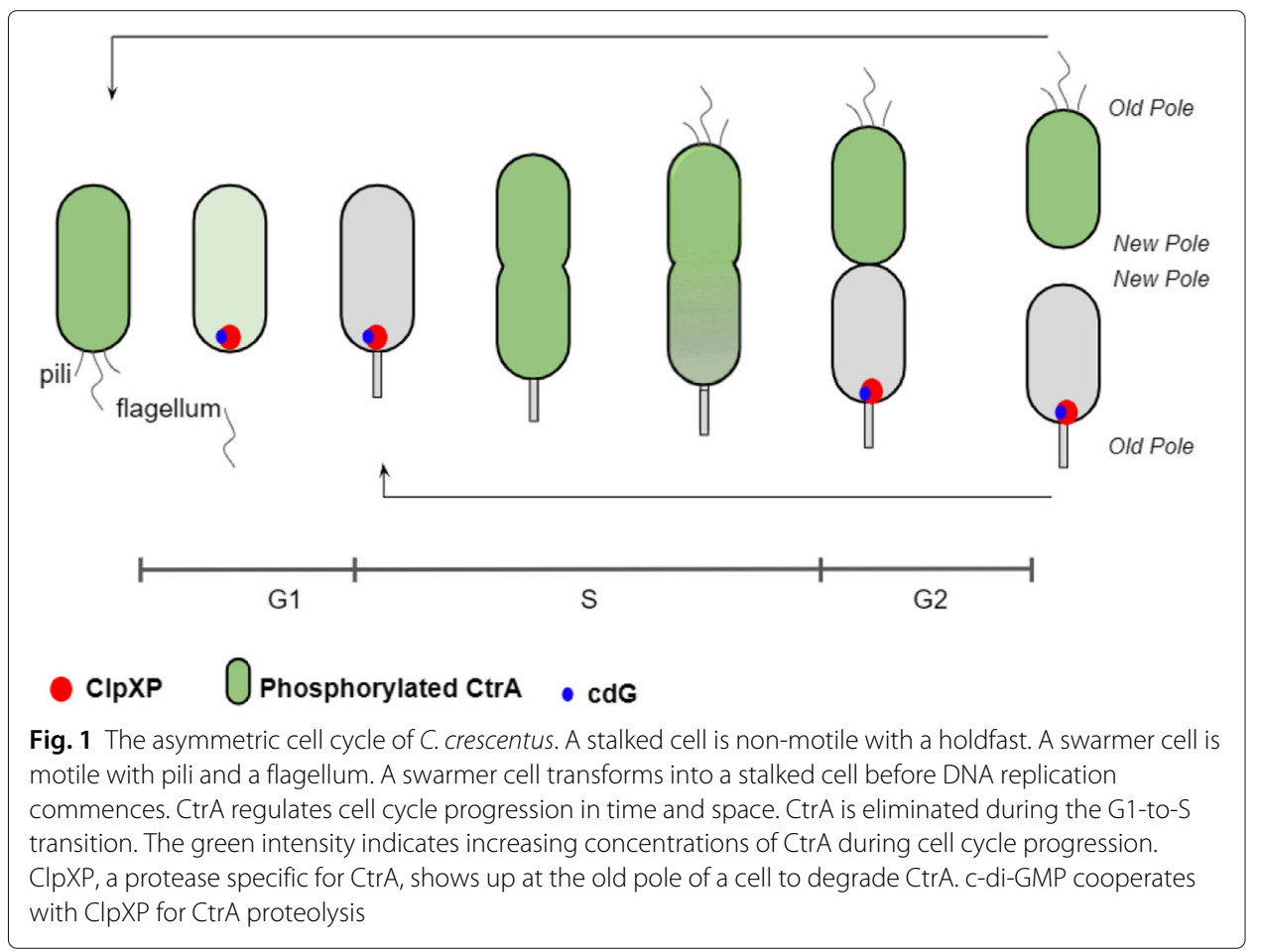


bacteria with similar characteristics. Many proteins, genes, and other molecules involved in the asymmetric pattern have been reported $[2,3]$. CtrA, a master regulator of the $C$. crescentus life cycle, regulates more than 100 genes involved in flagellum biogenesis, DNA replication, and cell division [4,5]. As CtrA inhibits the initiation of DNA replication, active CtrA (the phosphorylated form) must be eliminated during the swarmer-to-stalked (G1-to-S) transition. There are two pathways to inactivate CtrA: proteolysis by ClpXP [6] and dephosphorylation by CckA [7].

In C. crescentus, the spatio-temporally regulated proteolysis of CtrA requires protease ClpXP and additional factors called adaptors [6, 8]. The adaptor complex consists of CpdR, RcdA, PopA, and a second messenger c-di-GMP (cdG) (Fig. 2). ClpXP primed by unphosphorylated CpdR localizes at the old pole (Fig. 1) and recruits the adaptor RcdA which directly interacts with PopA. PopA must be bound with cdG to adapt CtrA to the entire protease complex (Fig. 2), which means cdG is indispensable for CtrA proteolysis. In addition to regulating CtrA proteolysis, $\mathrm{cdG}$ also participates in CtrA dephosporylation through CckA [7]. CckA is a bifunctional enzyme, which can act as both a phosphatase and a kinase to regulate CtrA and CpdR. When cdG binds with CckA, CckA activity favors the phosphatase state over the kinase state. When cdG level peaks during the G1-to-S transition, the dephosphorylation of CtrA and CpdR is rapidly stimulated, which allows DNA replication to initiate [9]. In this way, cdG stimulates DNA replication by activating the dephosphorylation and degradation of CtrA (Fig. 2).

While cdG stimulates the G1-to-S transition, alternative guanine-nucleotide based secondary messengers, guanosine tetraphosphate and guanosine pentaphosphate ((p)ppGpp), promote mobility and cell cycle arrest in C. crescentus. While the exact mechanisms are unknown, it is understood that (p)ppGpp indirectly promotes stablization of CtrA and degradation of DnaA, as well as interacting with RNA polymerase to influence global gene expression [10].

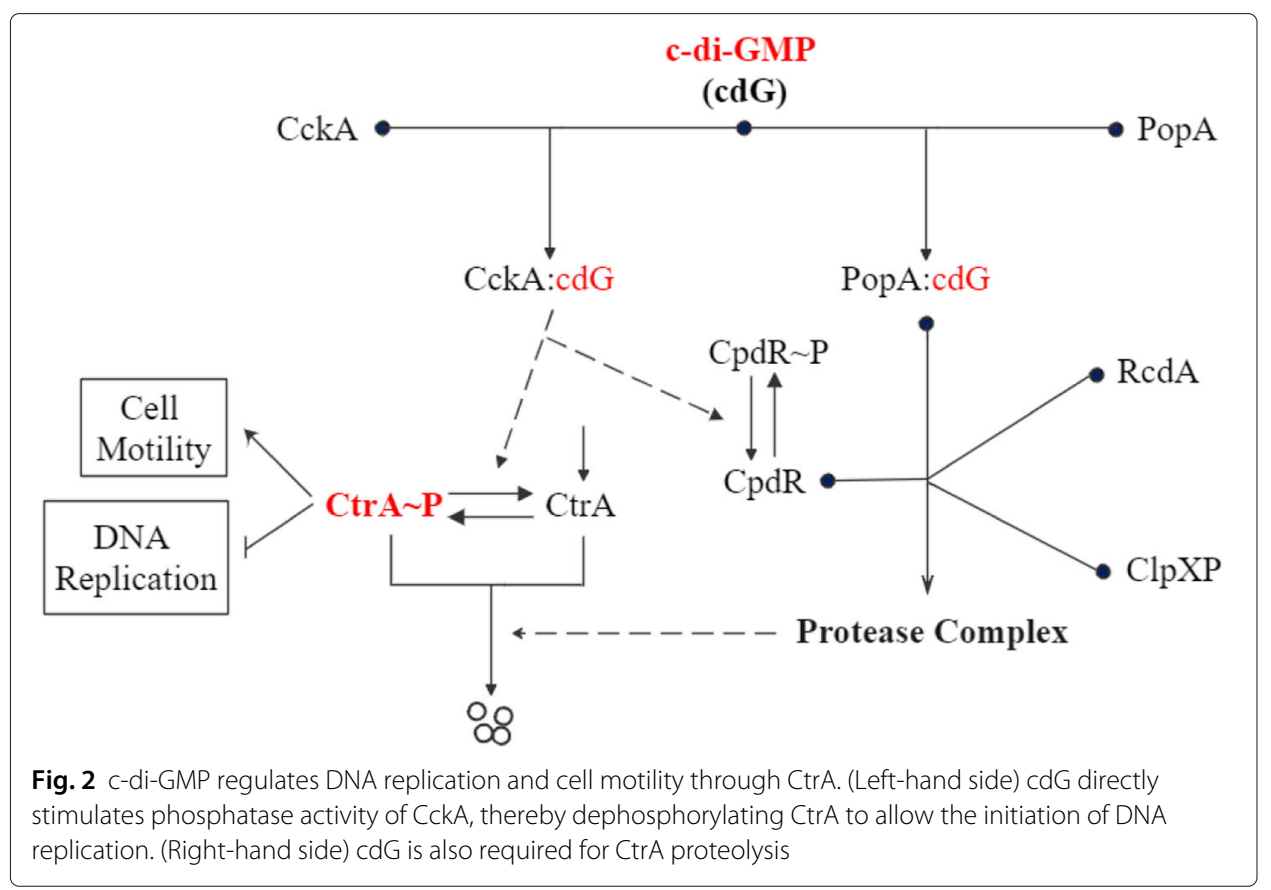


Additionally, cdG and (p)ppGpp control several key processes to help bacteria adjust to environmental cues, such as depletion of nutrients $[10,11]$. There is evidence that bacteria accumulate (p)ppGpp in response to carbon and/or nitrogen limitation [10] by regulating RelA-SpoT homolog (RSH) enzymes. Furthermore, bacteria respond to the availability of carbon through cdG-regulated signaling processes [11]. However, the specific mechanisms by which stressful conditions affect cell cycle progression through the second messenger system and other key proteins in C. crescentus is not clear.

In this work, we combine cdG, (p)ppGpp, and GTP into one mathematical model to investigate the dynamics of these second messengers and how they respond to environmental changes through the PTS ${ }^{\mathrm{Ntr}}$. Our model suggests that the concentration of cdG decreases dramatically following nitrogen deprivation in response to increased synthetase and decreased hydrolase activity of the bifunctional enzyme, SpoT. This observation suggests a novel mechanism by which $C$. crescentus may regulate its cell cycle in response to nitrogen availability. Our model also suggests that (p)ppGpp-associated stability of CtrA may be a result of reduced cdG activity due to depletion of GTP. The dynamics of PTS ${ }^{\mathrm{Ntr}}$ enzymes have not yet been measured experimentally, however our model predicts how they might behave under various levels of nitrogen availability. Intracellular glutamine, phosphoenolpyruvate (PEP), and pyruvate (Pyr) affect the phosphorylation state of PTS $^{\text {Ntr }}$ enzymes in our model, which suggests that a stringent response to nutrient availability by guanine nucleotide-based second messengers may be enforced through both glutamine level and the concentrations of PEP and pyruvate.

\section{Methods}

\section{Diagram construction}

\section{Metabolism and characterization of c-di-GMP}

The cellular concentration of cdG is regulated by its synthesis by diguanylate cyclases (DGCs) and its degradation by phosphodiesterases (PDEs) [12]. DGCs (like PleD and $\mathrm{DgcB}$ ), whose activities reside in the highly conserved GGDEF domain, act as dimers to produce cdG from two GTP molecules [13]. cdG negatively regulates its own synthesis by allosterically binding with the I-site of DGCs to inhibit synthetase activity [12].

PDEs (such as PdeA and PdeB) cleave cdG to linear diguanylate (pGpG) or to GMP, based on the conserved EAL domain or HD-GYP domain, respectively [13]. As pGpG is eventually converted into GMP (Fig. 3), we ignore pGpG in the model and consider two molecules of GMP as the product of cdG degradation. In addition, the activity of some PDEs in C. crescentus is activated by binding GTP [14]. The initial velocity of hydrolysis by PDEs reaches $\mathrm{V}_{\max } / 2$ when the concentration of GTP is $4 \mu \mathrm{M}$. Because GTP concentration in bacteria is much higher than $4 \mu \mathrm{M}$ [15-17], we assume PDEs are constantly saturated with GTP and do not include this interaction in our model.

\section{Metabolism and characterization of (p)ppGpp}

(p)ppGpp accumulates in most bacteria under stressful conditions, such as nutrient starvation $[10,18]$. In C. crescentus, (p)ppGpp delays the entry into $S$ phase and the swarmer-to-stalked cell transition. This response gives $C$. crescentus an advantage in 


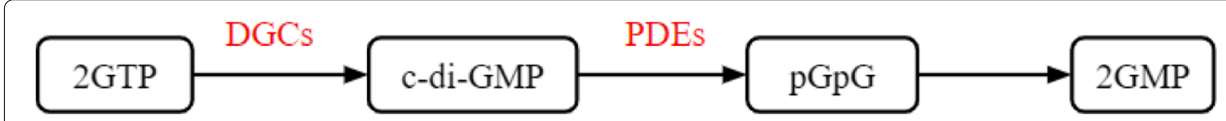

Fig. 3 Schematic diagram of cdG metabolism. DGCs catalyze the synthesis of cdG. PDEs cleave cdG into pGpG, which is subsequently cleaved to two molecules of GMP

nutrient-deprived environments by maintaining its mobility to search for better environments and by delaying DNA replication to conserve energy [11]. C. crescentus utilizes the bifunctional enzyme SpoT, an RSH homologue, to catalyze the conversion between (GTP)GDP and (p)ppGpp [18-20] (Figs. 4, 5).

It has been reported that (p)ppGpp inhibits the synthesis of GMP and GDP through binding the corresponding synthetases, such as HPRT, GMK, and their homologues $[21,22]$. The binding affinity of HPRT for pppGpp is $K_{\mathrm{d}}=3.38 \mu \mathrm{M}$ in E. coli, but only $0.24 \mu \mathrm{M}$ in C. crescentus [22]. We ignored this inhibition (Fig. 5) because the HPRT homologue should be saturated with basal levels of (p)ppGpp in bacteria (10-50 $\mu \mathrm{M}$ $[11,22])$.

\section{Nitrogen phosphotransferase system}

It has been well documented that (p)ppGpp responds to carbon and nitrogen deprivations $[11,19,21]$. While the specific mechanism underlying carbon starvation is not yet clear, the mechanism responsible for nitrogen starvation has been recently elucidated [10]. The accumulation of (p)ppGpp following nitrogen starvation is regulated by the nitrogen phosphotransferase system $\left(\right.$ PTS $\left.^{\mathrm{Ntr}}\right)[10,18]$.

The PTS ${ }^{\mathrm{Ntr}}$ consists of three components $\left(\mathrm{EI}^{\mathrm{Ntr}}, \mathrm{NPr}\right.$, and EIIA ${ }^{\mathrm{Ntr}}$ ) which form a phosphorylation cascade (Fig. 5). The first protein $\mathrm{EI}^{\mathrm{Ntr}}$ initiates the cascade through autophosphorylation using PEP as the phosphoryl donor. Then the phosphoryl group is transferred from $\mathrm{EI}^{\mathrm{Ntr}}$ to NPr and then to EIIA ${ }^{\mathrm{Ntr}}$. This process is reversible, so three components exchange phosphate groups and reach a steady state. EIIA ${ }^{\mathrm{Ntr}}$ can transfer its phosphate group to other unknown molecules [23]. We assume that the rate of phosphoryl transfer from EIIA ${ }^{\mathrm{Ntr}}$ to these other molecules outside of the PTS $^{\mathrm{Ntr}}$ is far slower than the transfer rate among PTS ${ }^{\mathrm{Ntr}}$ proteins and the exchange with PEP and pyruvate. Therefore, we do not include a terminal phosphate sink in our model of the PTS $^{\text {Ntr. }}$.

Glutamine binds to the conserved GAF domain of $\mathrm{EI}^{\mathrm{Ntr}}$ (Fig. 6) to prevent its autophosphorylation. Because glutamine works as a powerful nitrogen signal, enzymes involved in the PTS ${ }^{\text {Ntr }}$ become highly phosphorylated under nitrogen starvation when the intracellular level of glutamine decreases rapidly [10]. The PTS ${ }^{\text {Ntr }}$ influences cdG dynamics by its

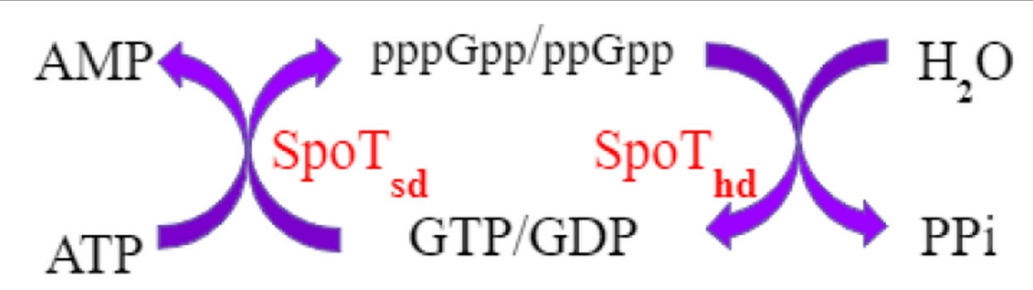

Fig. 4 Metabolism of (p)ppGpp. SpoT, a bifunctional enzyme in C. crescentus, catalyzes both the synthesis and hydrolysis of (p)ppGpp 

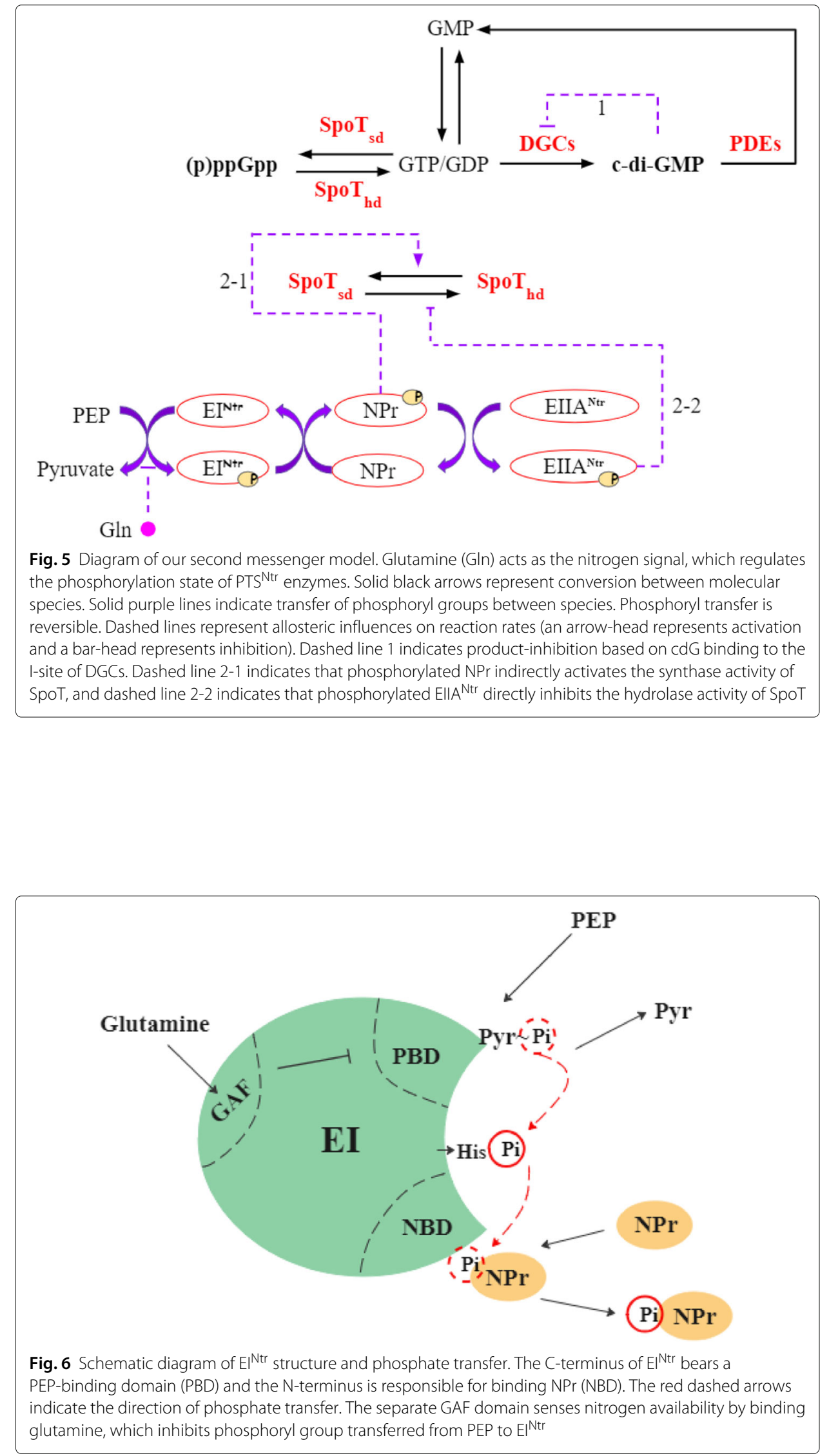
effects on SpoT activity. Bacterial two-hybrid assays and mutant experiments [18] indicate that phosphorylated EIIA ${ }^{\text {Ntr }}$ directly interacts with SpoT to inhibit hydrolase activity, whereas phosphorylated NPr activates SpoT synthetase activity indirectly (Fig. 5). In this way, the PTS $^{\text {Ntr }}$, which senses nitrogen availability through glutamine, subsequently regulates SpoT activity and (p)ppGpp levels.

\section{Mathematical model}

Based on the diagram in Fig. 5, the reactions of our model are as follows:

The activity of DGCs is subject to product inhibition through binding of cdG. As two cdG molecules bind allosterically to each DGC dimer, we assumed that cdG inhibition of DGC is a cooperative process. Thus we expressed the activity of [DGC] as a Hill function with a Hill exponent of 2 (Table 1, Eq. (1)). Unlike DGCs, PDEs act as monomers, which convert cdG to pGpG or GMP [13]. pGpG is subsequently converted into GMP [10]. We assumed this reaction is very fast and ignored the intermediate pGpG.

$$
\text { 2GTP } \stackrel{\text { DGCS }}{\longrightarrow} \text { c-di-GMP } \stackrel{\text { PDEs }}{\longrightarrow} \text { 2GMP. }
$$

As GDP and GTP can be interconverted and their products, ppGpp and pppGpp, behave similarly $[11,19,24]$, we lumped GDP and GTP into a single variable, 'GTP', and ppGpp and pppGpp are also condensed into one variable, (p)ppGpp. These 'variables' are interconverted by the synthetase and hydrolase activities of SpoT $\left(\mathrm{SpoT}_{\mathrm{sd}}\right.$ and $\mathrm{SpoT}_{\text {hd }}$, respectively). To take the direct and indirect effects of $\mathrm{NPr} \sim \mathrm{P}$ and $\mathrm{EIIA}^{\mathrm{Ntr}} \sim \mathrm{P}$ into consideration, we define a variable, $\alpha$ (Table 1), as the synthetase:hydrolase ratio of SpoT [25].

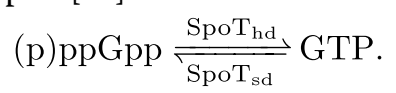

The interconversion of GTP, GDP and GMP is described compactly in our mathematical model by the reversible reaction

Table 1 Equations of our mathematical model*

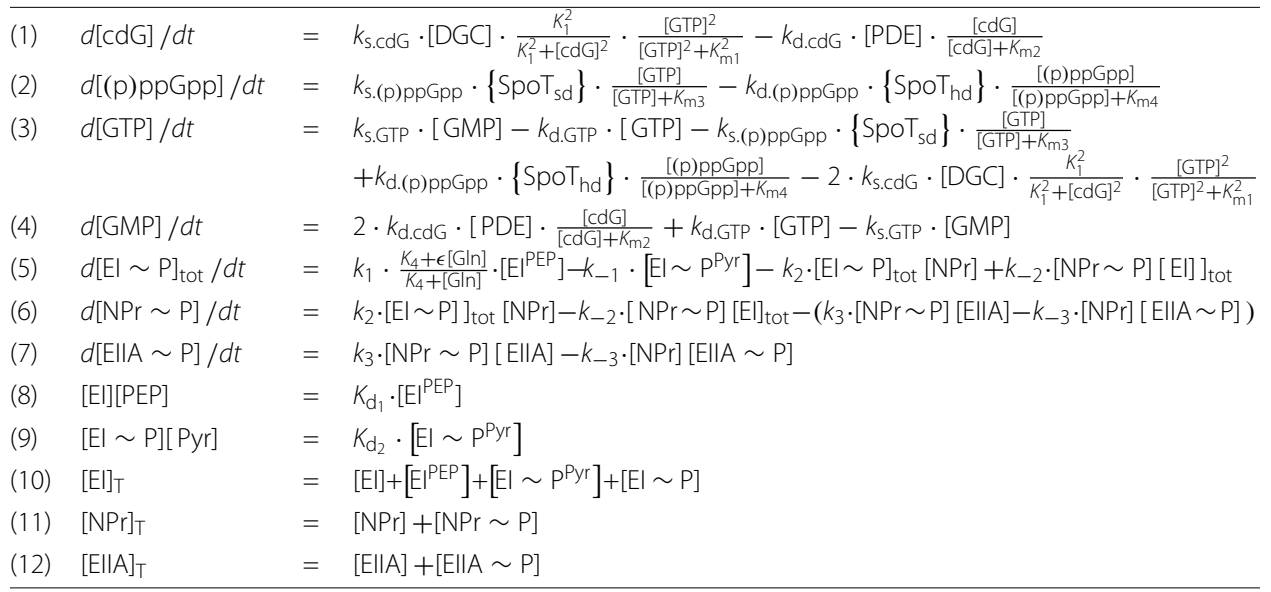

${ }^{*}\left\{\mathrm{SpoT}_{\mathrm{sd}}\right\}=\frac{\alpha}{1+\alpha},\left\{\mathrm{SpoT} \mathrm{T}_{\mathrm{hd}}\right\}=\frac{1}{1+\alpha}, \alpha=K_{\mathrm{SpoT}} \cdot \frac{[\mathrm{NPr} \sim \mathrm{P}]}{[\mathrm{NPr} \sim \mathrm{P}]+K_{2}} / \frac{K_{3}}{[\mathrm{EllA} \sim \mathrm{P}]+K_{3}} \cdot\left\{\mathrm{SpoT}_{\mathrm{sd}}\right\}$ and $\left\{\mathrm{SpoT}_{\text {hd }}\right\}$ represent the fraction of total SpoT for synthetase and hydrolase, respectively 
GTP $\underset{k_{\text {s.GTP }}}{\stackrel{k_{\text {d.GTP }}}{\rightleftharpoons}}$ GMP.

PEP binds to the C-terminal domain of EI and donates a phosphoryl group to His189 (Fig. 6). Then the phosphoryl group is transferred to the next two enzymes, NPr and EIIA ${ }^{\mathrm{Ntr}}$, in sequence [26, 27]. Glutamine binds to an allosteric site of $\mathrm{EI}^{\mathrm{Ntr}}$ (the GAF domain) [28] and inhibits phosphoryl transfer to His-189 [10, 29]. The phosphorylation cascade is summarized by the following reactions:

$$
\begin{gathered}
\mathrm{EI}+\mathrm{PEP} \underset{k_{\mathrm{b}_{-}}}{\stackrel{k_{\mathrm{b}_{1}}}{\rightleftharpoons}} \mathrm{EI}^{\mathrm{PEP}}, \\
\mathrm{EI}^{\mathrm{PEP}} \stackrel{k_{1} \text { (inhibited by Gln) }}{\rightleftharpoons k_{-1}} \mathrm{EI} \sim \mathrm{P}^{\mathrm{Pyr}}, \\
\mathrm{EI} \sim \mathrm{P}^{\mathrm{Pyr}} \underset{k_{\mathrm{b}_{2}}}{\frac{k_{\mathrm{b}_{-}}}{\rightleftharpoons}} \mathrm{EI} \sim \mathrm{P}+\mathrm{Pyr}, \\
\mathrm{EI} \sim \mathrm{P}_{\text {tot }}+\mathrm{NPr} \frac{k_{2}}{\stackrel{k_{-2}}{\rightleftharpoons}} \mathrm{EI} \mathrm{I}_{\text {tot }}+\mathrm{NPr} \sim \mathrm{P}, \\
\mathrm{NPr} \sim \mathrm{P}+\mathrm{EIIA} \underset{k_{-3}}{\stackrel{k_{3}}{\rightleftharpoons}} \mathrm{NPr}+\mathrm{EIIA} \sim \mathrm{P} .
\end{gathered}
$$

where $\mathrm{EI} \sim \mathrm{P}_{\text {tot }}=\mathrm{EI} \sim \mathrm{P}+\mathrm{EI} \sim \mathrm{P}^{\mathrm{Pyr}}$ and $\mathrm{EI}_{\mathrm{tot}}=\mathrm{EI}+\mathrm{EI}^{\mathrm{PEP}} . \mathrm{EI}^{\mathrm{PEP}}$ and $\mathrm{EI} \sim \mathrm{P}^{\mathrm{Pyr}}$ indicate $\mathrm{EI}$ bound with PEP and EI P bound with Pyr, respectively. $k_{ \pm i}(i=1,2,3)$ are the rate constants of phosphorylation reactions, while $k_{\mathrm{b}_{ \pm j}}(j=1,2)$ are the rate constants of binding reactions.

Here, we make several assumptions to describe PTS $^{\text {Ntr }}$ reactions effectively:

(1) As PEP binding to EI is a rapid process [26, 30], we assumed that PEP and Pyr binding reactions are much faster than phosphorylation reactions (reaching quasi-steady state) [26]. Therefore, we converted the binding reactions into algebraic equations (Table 1, Eqs. $(8,9)$ ).

(2) We assumed that $\mathrm{EI} \sim \mathrm{P}$ and $\mathrm{EI} \sim \mathrm{P}^{\mathrm{Pyr}}$ phosphorylate NPr at the same rate, but EI $\mathrm{I}^{\mathrm{Pyr}}$ is unstable and immediately dissociates into EI and Pyr. Similarly, we assumed that $\mathrm{EI}$ and $\mathrm{EI}^{\mathrm{PEP}}$ can be phosphorylated by $\mathrm{NPr} \sim \mathrm{P}$, but $\mathrm{EI} \sim \mathrm{P}^{\mathrm{PEP}}$ is unstable and immediately dissociates into EI $\sim \mathrm{P}$ and PEP.

(3) Since there is limited experimental data for the kinetic rate constants of the nitrogen PTS, we utilized experiments on the carbon PTS system to estimate these rate constants in our model. The kinetics of the carbon and nitrogen PTSs are likely very similar as they are homologues [31,32].

(4) The total concentrations of $\mathrm{EI}^{\mathrm{Ntr}}$, NPr and EIIA ${ }^{\mathrm{Ntr}}$ are assumed to be constants [33]. We estimated the total concentrations to be: $\left[\mathrm{EI}^{\mathrm{Ntr}}\right]_{\mathrm{T}}=10 \mu \mathrm{M},[\mathrm{NPr}]_{\mathrm{T}}=$ $30 \mu \mathrm{M}$, and [EIIA $\left.{ }^{\mathrm{Ntr}}\right]_{\mathrm{T}}=30 \mu \mathrm{M}[34-36]$.

The resulting mathematical model consists of seven ODEs and five algebraic equations (Table 1 and Additional file 1). Parameters are defined in Table 2. Whenever possible, we estimated parameters from experimental data. Initial conditions in Table 3 
were estimated from the intracellular concentrations in bacteria. The maximum concentration of cdG in C. crescentus is around $0.28 \mu \mathrm{M}$ [37]. The basal levels of (p)ppGpp and GTP in Gram-negative bacteria during normal conditions are around $50 \mu \mathrm{M}$ and $1000 \mu \mathrm{M}$ [15], respectively. The ratio of [(p)ppGpp] to [GTP] in C. crescentus varies from 0.15 to 1.9 under rich and limited nitrogen conditions [20, 38, 39]. We used these values to calibrate our model. The ODEs were solved in MATLAB with ode15s.

\section{Simulations and results}

\section{Oscillations of DGCs and PDEs}

Two well-known DGCs in C.crescentus are $\mathrm{DgcB}$ and PleD [37, 41]. During progression through the cell cycle, $\mathrm{DgcB}$ level stays constant, but the concentration and activity of PleD vary [41]. Hence, we model [DGC] as the sum of constant $[\mathrm{DgcB}]$ and variable $[\mathrm{PleD}]$. Because experimental data on the fluctuation of active (phosphorylated) PleD over the course of the C. crescentus cell cycle is not available, we used total PleD flucutations as a substitute. Figure 7 a shows immunoblot measurements (red dots) of total PleD, extracted by ImageJ from [41], and the corresponding curve fitted by MATLAB (R-square is 0.66). It appears that the second data point from Abel et al. [41] is inaccurate because PleD activity should peak around $t=20$, since $c d G$ needs to be produced at a

Table 2 Parameters

\begin{tabular}{|c|c|c|}
\hline Parameter & Description & Source \\
\hline$k_{\mathrm{s} . \mathrm{cdG}}=33.5 / \mathrm{min}$ & scaled synthesis rate of $\mathrm{cdG}$ & this study \\
\hline$k_{\mathrm{d}, \mathrm{cdG}}=100 / \mathrm{min}$ & scaled degradation rate of $\mathrm{cdG}$ & this study \\
\hline$K_{1}=0.5 \mu \mathrm{M}$ & dissociation constant for product inhibition & {$[40]$} \\
\hline$K_{\mathrm{m} 1}=1500 \mu \mathrm{M}$ & binding affinity of GTP & this study \\
\hline$K_{\mathrm{m} 2}=0.06 \mu \mathrm{M}$ & binding affinity of $c d G$ & {$[40]$} \\
\hline$[\mathrm{DgcB}]=0.7 \mu \mathrm{M}$ & scaled DgcB level & {$[41]$} \\
\hline [ basal PDEs] $=0.2 \mu \mathrm{M}$ & scaled basal PDE level & this study \\
\hline$k_{\mathrm{s} .(\mathrm{p}) \mathrm{ppGpp}}=170 \mu \mathrm{M} / \mathrm{min}$ & synthesis rate of (p)ppGpp & this study \\
\hline$k_{\text {d.(p)ppGpp }}=160 \mu \mathrm{M} / \mathrm{min}$ & degradation rate of (p)ppGpp & this study \\
\hline$K_{2}=75 \mu \mathrm{M}$ & binding affinity of $N P r \sim P$ & this study \\
\hline$K_{3}=10 \mu \mathrm{M}$ & dissociation constant of EllA $\sim P$ & this study \\
\hline$K_{\text {SpoT }}=4$ & constant of SpoT activity & this study \\
\hline$K_{\mathrm{m} 3}=1000 \mu \mathrm{M}$ & binding affinity of GTP & this study \\
\hline$K_{\mathrm{m} 4}=2000 \mu \mathrm{M}$ & binding affinity of (p)ppGpp & this study \\
\hline $\begin{array}{l}K_{4}=75.63 \mu \mathrm{M} \\
\epsilon=0.1\end{array}$ & parameters of glutamine inhibition & {$[42]$} \\
\hline$k_{\mathrm{S} . \mathrm{GTP}}=1500 / \mathrm{min}$ & synthesis rate of GTP & this study \\
\hline$k_{\mathrm{d} . G T P}=100 / \mathrm{min}$ & degradation rate of GTP & this study \\
\hline$[\mathrm{El}]_{\mathrm{T}}=10 \mu \mathrm{M}$ & \multirow{3}{*}{ total enzymes levels } & \multirow{3}{*}{ [34-36] } \\
\hline$[\mathrm{NPr}]_{\top}=30 \mu \mathrm{M}$ & & \\
\hline$[E \|]_{\top}=30 \mu \mathrm{M}$ & & \\
\hline$k_{1}=52.4 / \mathrm{min}$ & \multirow{3}{*}{ phosphotransfer constants } & \multirow[t]{2}{*}{ this study, $[27,42]$} \\
\hline $\begin{array}{l}k_{-1}=67.2 / \mathrm{min} \\
k=12 \times 10^{4} /(\mathrm{min} \cdot\end{array}$ & & \\
\hline $\begin{array}{l}k_{ \pm 2}=1.2 \times 107(\min \cdot \mu \mathrm{M}) \\
k_{ \pm 3}=3.7 \times 10^{3} /(\min \cdot \mu \mathrm{M})\end{array}$ & & {$[27,33]$} \\
\hline $\begin{array}{l}K_{\mathrm{d} 1}=\frac{k_{b_{-1}}}{k_{b_{1}}}=350 \mu \mathrm{M} \\
K_{\mathrm{d} 2}=\frac{k_{b_{-2}}}{k_{b_{2}}}=670 \mu \mathrm{M}\end{array}$ & dissociation constants & {$[27]$} \\
\hline
\end{tabular}


Table 3 Initial conditions

\begin{tabular}{ll}
\hline Variables & Initial Conditions $(\mu$ M) \\
\hline C-di-GMP & 0.3 \\
GTP & 1300 \\
(p)ppGpp & 100 \\
GMP & 20 \\
EI P & 10 \\
NPr $\sim P$ & 30 \\
EIIA P & 30 \\
\hline
\end{tabular}

high level at this time to deplete active CtrA and initiate the G1-to-S transition. Assuming that the second experimental point is an error, we re-fit the total PleD without this point (Fig. 7b, R-square is 0.84 ). In agreement with our expectations, the fitted curve in Fig. 7b increases during G1-to-S transition and peaks around $30 \mathrm{~min}$. The corresponding accuracy of curve fitting improves as well. Additionally, we borrowed the active PleD simulation of an as-yet unpublished model by Bronson Weston (Fig. 7c, magenta curve) which captures the dynamics of phosphorylation of PleD. Weston's simulation of PleD P (Fig. 7c) shows a similar trend with the experimental data and re-fitted curve of total PleD (Fig. 7b,c), which serves to justify our methods for calibrating a curve for PleD activity. The different scaled levels between Weston's simulation and experimental points are due to different normalization methods.

While PdeA is the most active phosphodiesterase enzyme in C. crescentus [44], other PDEs, including PdeB, PdeC, and PdeD, have been identified in bacterial species $B$. subtilis, E. coli and L. monocytogenes [45]. Assuming there are other PDEs in C. crescentus

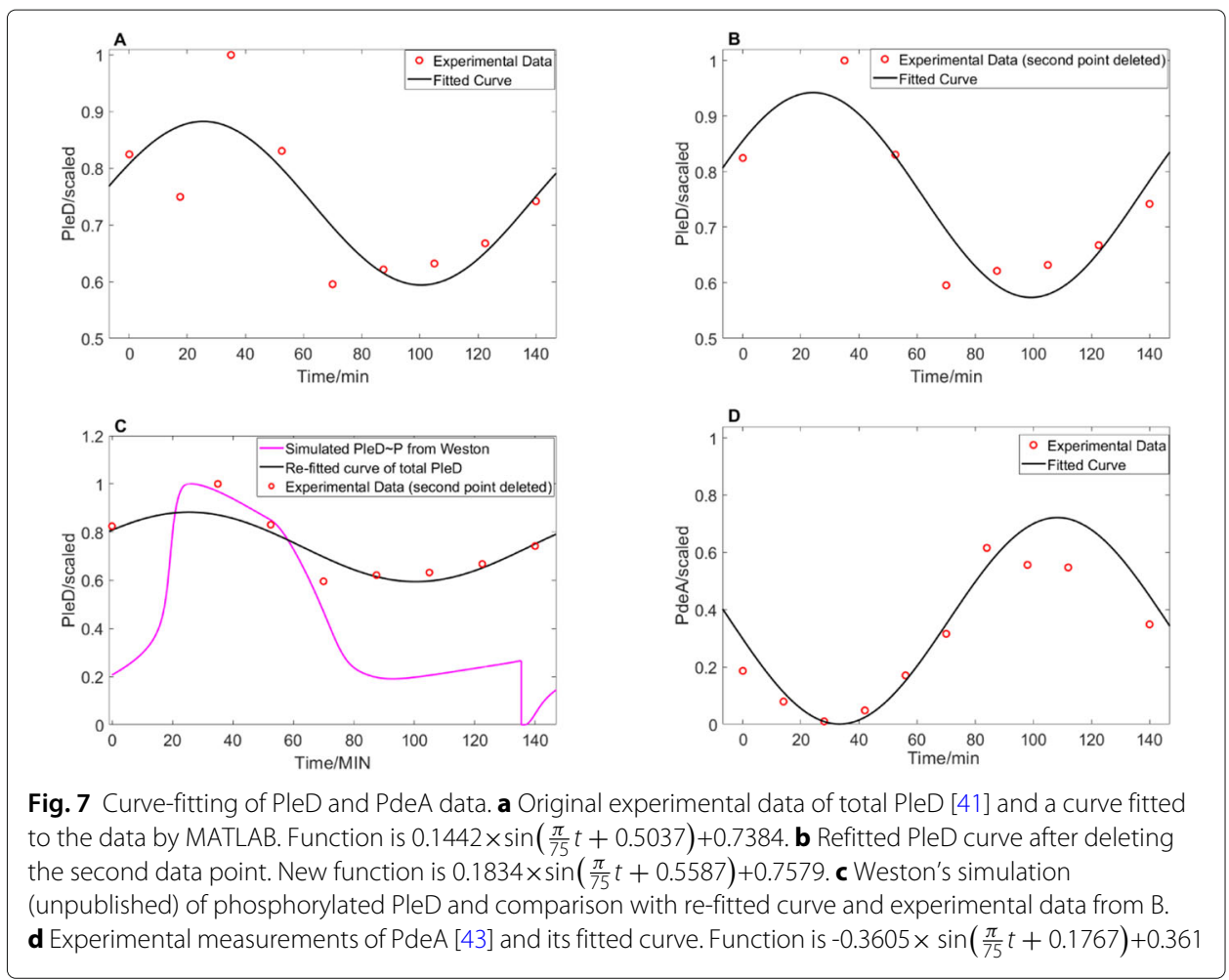


as well, we represented total [PDE] in our model as the sum of [basal PDE] plus a variable [PdeA] estimated by the curve-fitting tool in MATLAB applied to quantitative PdeA measurements derived from Western blots of [46] using ImageJ. The PdeA points and the corresponding curve are shown in Fig. $7 \mathrm{~d}$ with R-square being 0.77 .

\section{Oscillation of c-di-GMP over cell cycle in C. crescentus}

We used experimental data of cdG concentration (peak point) [37] and bacterial nucleotide concentrations to estimate parameters that are not available in publications. Experimentally, cdG peaks at the swarmer-to-stalked transition $(\approx 0.28 \mu \mathrm{M})$ and then decreases until reaching the lowest value $(<0.1 \mu \mathrm{M})$ in the swarmer cell after cell division. Our simulation of cdG over time fits experimental data well and shows a stable oscillation through the cell cycle under nutrient-rich conditions (Fig. 8), in agreement with experimental data [37].

\section{Comparison of simulated PTS ${ }^{\mathrm{Ntr}}$ to carbon-PTS experimental data}

PTS and PTS ${ }^{\mathrm{Ntr}}$ have a lot in common. Enzymes of PTS ${ }^{\mathrm{Ntr}}\left(\mathrm{EI}^{\mathrm{Ntr}}\right.$, NPr, and EIIA $\left.{ }^{\mathrm{Ntr}}\right)$ are homologues of carbon-PTS enzymes (EI, HPr, and EIIA/B/C) [31]. They have similar structures and play parallel roles in nutrient uptake. In addition, these PTSs communicate with each other by phosphate exchange [28, 47]. PEP acts as the phosphoryl donor for both carbon and nitrogen PTSs. There are two significant differences between these systems [28]: (1) Enzymes II in PTS (juxtamembrane EIIB and transmembrane EIIC) assist in transmembrane transport of sugars [48] whereas PTS ${ }^{\mathrm{Ntr}}$ does not aid in sugar transport [32]. (2) PTS ${ }^{\mathrm{Ntr}}$ is regulated by glutamine levels as part of the nitrogen signaling pathway in prokaryotes, while PTS senses carbon sources in the environment through regulating transport and phosphorylation of carbohydrates like glucose [34, 49].

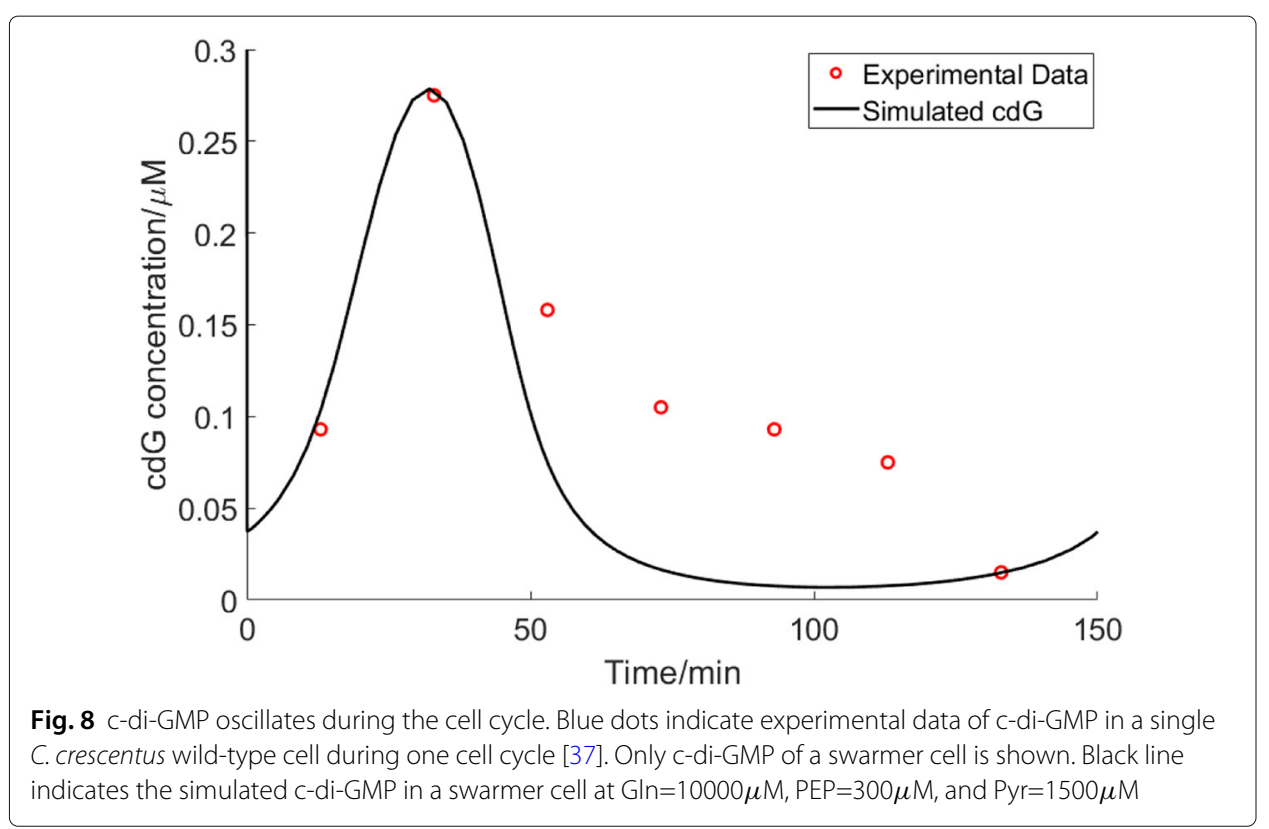


There is limited quantitative data for PTS ${ }^{\mathrm{Ntr}}$ in publications. Based on the similarities between PTS ${ }^{\text {Ntr }}$ and PTS, we introduced some parameters obtained from PTS experiments to simulate PTS $^{\mathrm{Ntr}}[27,33]$ (Table 2). In order to calibrate the PTS ${ }^{\mathrm{Ntr}}$ model, we set [Gln] to 0 and compared simulations with carbon PTS experiments.

Kundig and Roseman $[26,50]$ measured how EI and HPr levels affect phosphorylation of PTS quantitatively (Table 4). We set our initial conditions to the experimental conditions of the paper, substituting [Npr] and $\left[\mathrm{EI}^{\mathrm{Ntr}}\right]$ for $[\mathrm{Hpr}]$ and $[\mathrm{EI}]$, respectively. As there is no information about pyruvate concentrations in their experiments, we estimated the [Pyr] based on one set of experimental data in Table 4. The Table indicates that our PTS ${ }^{\mathrm{Ntr}}$ simulations fit the experimental data well.

\section{Simulations under different nutrients conditions}

Goodwin et al. [42] measured quantitatively how glutamine inhibits $\mathrm{EI}^{\mathrm{Ntr}}$ activity. In Table 5, we show model simulations under a range of glutamine levels. Lee et al. [51] showed that cellular glutamine in $E$. coli is very low under nitrogen-starvation and increases to more than $10000 \mu \mathrm{M}$ when environmental ammonium is increased. Therefore, in our simulations, we used $[\mathrm{Gln}]=1 \mu \mathrm{M}$ to represent limited nitrogen and [Gln] $=10000 \mu \mathrm{M}$ to describe abundant nitrogen.

PEP, the phosphoryl donor of PTS ${ }^{\mathrm{Ntr}}$, is an important indicator of carbon availability [52]. However, Osanai et al. [53] and Yuan et al. [54] showed that PEP and Pyr levels are stable under nitrogen shifts. Hogema et al. [55] measured intracellular PEP and Pyr in E. coli under different carbon conditions: cells were initially grown in minimal medium (ammonia with limited carbon) and had PEP and pyruvate concentrations of $2800 \mu \mathrm{M}$ and $[\mathrm{Pyr}]=900 \mu \mathrm{M}$, respectively. After adding $10 \mathrm{mM}$ glucose to the medium (now ammonia with high carbon), PEP and pyruvate concentrations shifted to $300 \mu \mathrm{M}$ and $1500 \mu \mathrm{M}$, respectively. In consideration of this experimental data, we set ' $[\mathrm{PEP}]=300 \mu \mathrm{M},[\mathrm{Pyr}]=1500 \mu \mathrm{M},[\mathrm{Gln}]=10000 \mu \mathrm{M}$ ' to represent 'ammonia with high carbon'; and ' $[\mathrm{PEP}]=300 \mu \mathrm{M},[\mathrm{Pyr}]=1500 \mu \mathrm{M},[\mathrm{Gln}]=1 \mu \mathrm{M}$ ' to represent 'nitrogen-starved' condition. As cells require carbon and nitrogen to synthesize glutamine, we regard limited glutamine (proposed as $1000-2000 \mu \mathrm{M}$ in Table 5) and ' $[\mathrm{PEP}]=2800 \mu \mathrm{M}$ and $[\mathrm{Pyr}]=900 \mu \mathrm{M}$ ' as 'ammonia with limited carbon'.

Table 5 summarizes the results of our simulations. cdG oscillations peak at $0.28 \mu \mathrm{M}$ under 'ammonia with high carbon', and peak at $0.02 \mu \mathrm{M}$ under nitrogen depletion. These

Table 4 Effect of El and HPr (NPr) concentrations on phosphorylation of El and HPr (NPr) in PTS system

\begin{tabular}{|c|c|c|c|}
\hline \multicolumn{2}{|c|}{ Condition } & \multirow{2}{*}{$\begin{array}{l}\text { Experiment }{ }^{*}[50] \\
\text { El } \sim \mathrm{P}+\mathrm{HPr} \sim \mathrm{P}(\mu \mathrm{M})\end{array}$} & \multirow{2}{*}{$\begin{array}{l}\text { Simulation } \\
\text { El } \sim \mathrm{P}+\mathrm{NPr} \sim \mathrm{P}(\mu \mathrm{M})\end{array}$} \\
\hline$\overline{\mathrm{El}(\mu \mathrm{M})}$ & $\mathrm{HPr}(\mathrm{NPr})(\mu \mathrm{M})$ & & \\
\hline 0.157 & 24.4 & 6 & 6.8 \\
\hline 0.3125 & 24.4 & 6.5 & 6.9 \\
\hline 0.729 & 24.4 & 7 & $7^{* *}$ \\
\hline 1.57 & 24.4 & 7.5 & 7.2 \\
\hline 0.729 & 0 & $>0 * * *$ & 0.2 \\
\hline 0.729 & 12.2 & 3 & 3.6 \\
\hline 0.729 & 36.6 & 9.1 & 10.5 \\
\hline
\end{tabular}

${ }^{*} \mathrm{PEP}=160 \mu \mathrm{M}$

*** This row has been used to estimate Pyr level; Pyr $=48.5 \mu \mathrm{M}$

*** Too small to recognize the specific value from the original figure [50] 
Table 5 Simulations under different conditions

\begin{tabular}{|c|c|c|c|c|c|c|c|}
\hline & {$[G \ln ]$} & $10000 \mu \mathrm{M}$ & $2000 \mu \mathrm{M}$ & $1000 \mu \mathrm{M}$ & $100 \mu \mathrm{M}$ & $10 \mu \mathrm{M}$ & $1 \mu \mathrm{M}$ \\
\hline & cdG range & $0.01-0.28^{*}$ & $0.01-0.26$ & $0.01-0.25$ & $0-0.09$ & $0-0.03$ & $0-0.02^{* *}$ \\
\hline & (p)ppGpp $(\mu \mathrm{M})$ & 118 & 150 & 187 & 582 & 895 & 939 \\
\hline & $\mathrm{GTP}(\mu \mathrm{M})$ & 1221 & 1192 & 1156 & 787 & 493 & 452 \\
\hline$[\mathrm{PEP}]=300 \mu \mathrm{M}$ & $\frac{[(\mathrm{p}) \mathrm{ppGpp}]}{[\mathrm{GTP}]}$ & 0.10 & 0.13 & 0.16 & 0.74 & 1.8 & 2.1 \\
\hline \multirow[t]{7}{*}[\mathrm{Pyr}]{$=1500 \mu \mathrm{M}$} & $\mathrm{GMP}(\mu \mathrm{M})$ & 81 & 79 & 77 & 52 & 33 & 30 \\
\hline & $\mathrm{El} \sim \mathrm{P}(\mu \mathrm{M})$ & 0.5 & 0.6 & 0.8 & 2.0 & 3.2 & 3.4 \\
\hline & $\mathrm{NPr} \sim \mathrm{P}(\mu \mathrm{M})$ & 1.6 & 1.9 & 2.4 & 6.1 & 9.5 & 10.2 \\
\hline & $\mathrm{E} I \mathrm{~A} \sim \mathrm{P}(\mu \mathrm{M})$ & 1.6 & 1.9 & 2.4 & 6.1 & 9.5 & 10.2 \\
\hline & cdG range & $0.01-0.20$ & $0.01-0.17^{* * *}$ & $0.01-0.13^{* * *}$ & $0-0.02$ & $0-0.01$ & $0-0.01$ \\
\hline & (p)ppGpp $(\mu \mathrm{M})$ & 294 & 371 & 458 & 993 & 1160 & 1178 \\
\hline & $\mathrm{GTP}(\mu \mathrm{M})$ & 1056 & 984 & 902 & 401 & 244 & 227 \\
\hline$[\mathrm{PEP}]=2800 \mu \mathrm{M}$ & $\frac{[(p) p p G p p]}{[G T P]}$ & 0.28 & 0.38 & 0.51 & 2.5 & 4.8 & 5.2 \\
\hline \multirow[t]{4}{*}[\text{Pyr}]{$=900 \mu \mathrm{M}$} & $\mathrm{GMP}(\mu \mathrm{M})$ & 70 & 66 & 60 & 27 & 16 & 15 \\
\hline & $\mathrm{El} \sim \mathrm{P}(\mu \mathrm{M})$ & 1.1 & 1.4 & 1.6 & 3.7 & 5.2 & 5.4 \\
\hline & $\mathrm{NPr} \sim \mathrm{P}(\mu \mathrm{M})$ & 3.4 & 4.2 & 4.9 & 11.1 & 15.6 & 16.3 \\
\hline & $\mathrm{E} I I \mathrm{~A} \sim \mathrm{P}(\mu \mathrm{M})$ & 3.4 & 4.2 & 4.9 & 11.1 & 15.6 & 16.3 \\
\hline
\end{tabular}

"Proposed to be under condition of ammonia with high carbon

**Proposed to be under condition of nitrogen starvation

**** Proposed to be under condition of ammonia with limited carbon

results suggest that depletion of nitrogen should result in cell cycle arrest, which is consistent with experimental observations [56]. In general, as glutamine concentrations decrease, cdG, GTP and GMP levels decrease while (p)ppGpp levels increase.

When we simulate conditions of 'ammonia with limited carbon', we find that cdG oscillations decrease in amplitude; however, concentrations are presumably not so low to induce cell cycle arrest. Thus, our results are consistent with the fact that $C$. crescentus continues to grow under such conditions [55]. Interestingly, our results suggest that (p)ppGpp levels should increase when decreasing carbon availability. Our results suggest that shifts in PEP and pyruvate concentrations due to limiting carbon availability will make the cell more sensitive to shifts in nitrogen. Table 5 suggests, that shifts in the direction of increased [PEP] and decreased [Pyr] favor increased activity in SpoT synthetase. Based on steady state analysis of ODEs in our model, phosphorylation of PTS ${ }^{\mathrm{Ntr}}$ proteins depends non-linearly on the [PEP]:[Pyr] ratio (Additional file 2). Increases in the ratio generally trend towards SpoT synthetase activity, while decreases trend toward hydrolase activity.

Our simulations show that the shift of c-di-GMP and (p)ppGpp levels in response to changes of nutrients is due to both a shift in internal glutamine concentration and an adjustment to the PEP and pyruvate levels (Table 5). Our model suggests that the PEP and Pyr levels regulating PTS ${ }^{\mathrm{Ntr}}$ is one potential pathway of (p)ppGpp response to carbon availability. Enzymes within the PTS ${ }^{\mathrm{Ntr}}$ system become highly phosphorylated under nitrogen starvation (Table 5), which is consistent with the existing qualitative analysis as well [10]. Additionally, our simulation fits the experimental observations (Table 6) well.

\section{Response to environmental change}

Given the oligotrophic environments $C$. crescentus populates, we postulate that $C$. crescentus would have to respond rapidly to sudden shifts in nutrients in order to increase 
Table 6 Experimental information for concentrations and changes under starvation

\begin{tabular}{lllll}
\hline Variables & Nutrient-rich & Nutrient-starved & Species & Reference \\
\hline (p)ppGpp & $50 \mu \mathrm{M}$ & - & E.coli & {$[11]$} \\
& $10-30 \mu \mathrm{M}$ & millimolar & B.subtilis & {$[22]$} \\
& $900 \mu \mathrm{M}$ & - & E.coli & {$[16]$} \\
GTP & - & 3 -fold drop (arginine starved) & B.subtilis & {$[21]$} \\
& $1000-3000 \mu \mathrm{M}$ & - & B.subtilis & {$[17]$} \\
& - & 3 -fold drop (glucose starved) & marine Vibrio & {$[57]$} \\
GDP & $100 \mu \mathrm{M}$ & - & E.coli & {$[16]$} \\
& - & 14 -fold drop (arginine starved) & B.subtilis & {$[21]$} \\
GMP & $24 \mu \mathrm{M}$ & - & E.coli & {$[58]$} \\
[pppGpp]:[GTP] ratio & $\approx 0.1$ & $\approx 0.3$ (arginine starved) & B.subtilis & {$[38]$} \\
& 0.08 & - & E.coli & {$[59]$} \\
& $\approx 0.25$ & $\approx 1.2$ (arginine starved) & B.subtilis & {$[38]$} \\
[ppGpp]:[GTP] ratio & 0.16 & - & E.coli & {$[59]$} \\
& $\approx 0.1$ & $\approx 1.5$ (arginine starved) & C.crescentus & {$[20]$} \\
\hline
\end{tabular}

its fitness in these environments. Figure 9 shows how C. crescentus responds to environmental nitrogen-shifts in our simulation. The response time for starvation is within one cell replication cycle, which means $C$. crescentus can respond to nutrient deprivation quickly according to our model. Perhaps even more importantly, our model suggests that C. crescentus also recovers quite quickly to normal cell cycle oscillations when we reset glutamine to the starting value. A response within the time frame of one cell cycle would be a useful characteristic for $C$. crescentus to survive in oligotrophic environments.

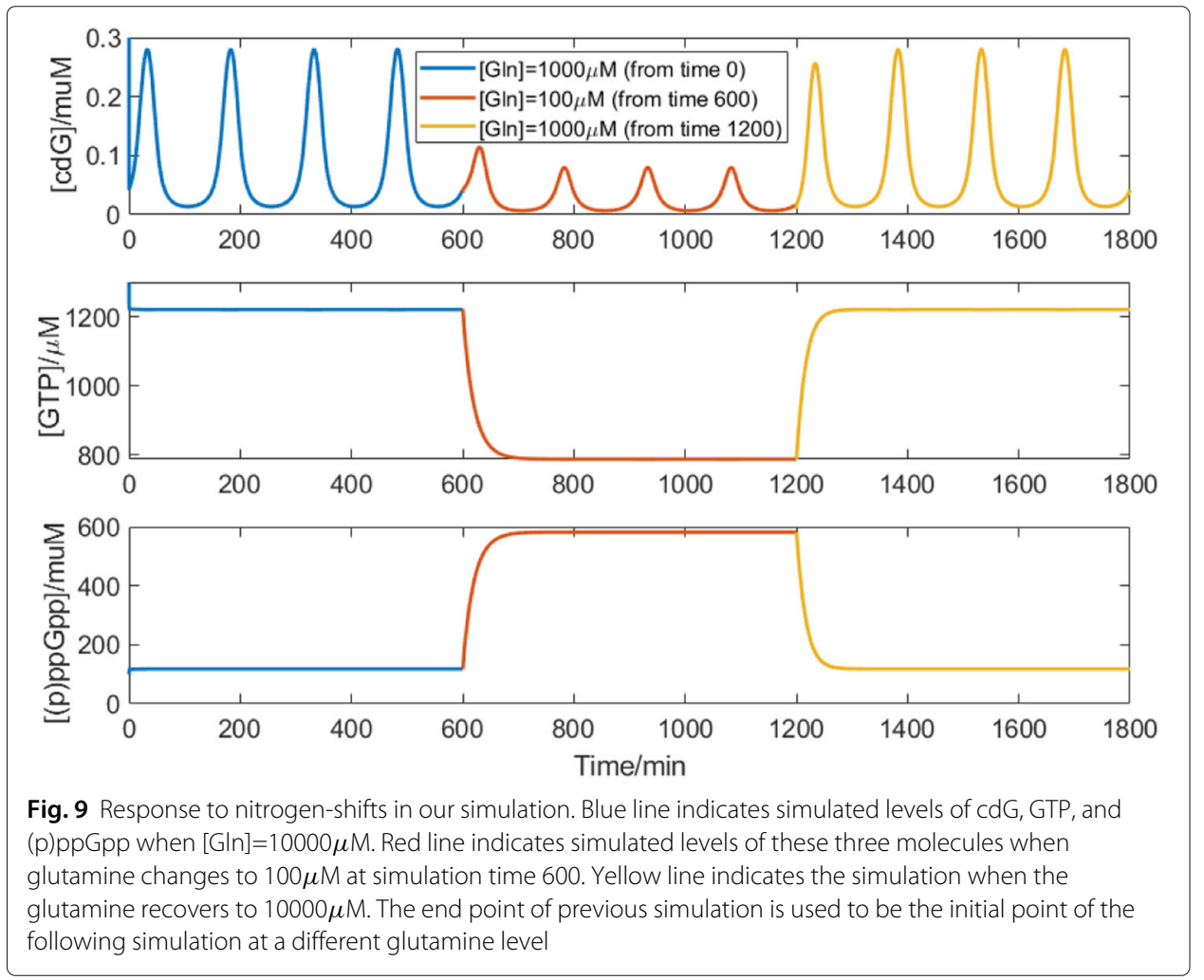




\section{Discussion}

Progression through the cell cycle in C. crescentus requires precise coordination of metabolic and morphological events. The guanine nucleotide-based second messenger network, including cdG and (p)ppGpp, plays significant roles in regulating bacterial morphology and metabolism, such as controlling the activity of CtrA and adapting bacteria to environmental changes. In this study, we propose a mathematical model to simulate the guanine nucleotide-based second messenger network, and investigate how this network responds to nutrient shifts through $\mathrm{PTS}^{\mathrm{Ntr}}$.

We calibrate our model using experimental data, and investigate two aspects influencing phosphorylation of PTS $^{\mathrm{Ntr}}$ in simulations: 1) glutamine levels, which affects autophosphorylation of EI ${ }^{\mathrm{Ntr}}$ [10, 28]; and 2) PEP and Pyr levels, which influence the flux of phosphorus through the PTS ${ }^{\mathrm{Ntr}}$ system (Table 5, Additional file 2).

Simulations of nitrogen deprivation suggest that as (p)ppGpp accumulates in C. crescentus, GTP and cdG concentrations decrease significantly as a result of increasing SpoT synthetase activity. While it is suggested that (p)ppGpp stabilizes CtrA in C. crescentus [60], the exact mechanism is unknown. As cdG is essential for CtrA proteolysis, the stability of CtrA may increase due to diminished cdG concentration as a result of SpoT synthetase activity, rather than downstream effects of (p)ppGpp signaling. Thus, we propose that $C$. crescentus may respond to nitrogen starvation by stimulating the PTS ${ }^{\mathrm{Ntr}}$ system to induce SpoT synthetase activity, resulting in depletion of GTP and cdG levels to induce cell cycle arrest via stabilization of the chromosome replication inhibitor, CtrA.

Importantly, our results also suggest that changes to intracellular concentrations of PEP and pyruvate can have a significant impact on SpoT activity. We find that shifts in PEP and pyruvate concentrations in response to decreased sugar availability result in an increase in SpoT synthetase activity and an increase in sensitivity to shifts in glutamine concentration. Thus, two potential avenues to influence the PTS ${ }^{\mathrm{Ntr}}$ and SpoT are through adjusting PEP and pyruvate levels as well as glutamine.

\section{Conclusions and future work}

Our mathematical model of guanine nucleotide-based second messenger network in $C$. crescentus (Fig. 5) agrees with experimental observations compiled from the literature. Most previous research has focused separately on cdG [14,37] dynamics or the PTS ${ }^{\mathrm{Ntr}}$ system $[10,42]$ in bacteria, but has never related the second messenger network with the PTS $^{\mathrm{Ntr}}$ system in order to study environmental impacts.

In this work, the interactions within the guanine nucleotide-based second messenger network are converted into a set of differential and algebraic equations (Table 1) to simulate second messenger response to nutrient conditions. cdG and (p)ppGpp, which play significant roles in cell cycle regulation, are connected with PTS $^{\mathrm{Ntr}}$ to explain the relationship between bacterial development and environmental changes.

The current model consists of seven ODEs and five algebraic equations, describing the synthesis, degradation, activation, inhibition, phosphorylation, dephosphorylation, binding, and release of physiological variables in C. crescentus. Our resulting simulations are in good agreement with experiments and our model makes several intriguing predictions, however there are still several exciting directions that we can take this model: 
(1) To better understand how nitrogen signaling influences the cell cycle of bacteria, we can combine this second messenger model with a detailed regulatory model of the $C$. crescentus cell cycle [61]. It will be interesting to see if a shift in cdG concentration due to changes in SpoT activity will be enough to induce cell cycle arrest, or if intervention by (p)ppGpp is also necessary.

(2) $[\mathrm{PEP}]$ and $[\mathrm{Pyr}]$ are adjustable signals in our model rather than variables. In the future, we hope to expand our model to include [PEP] and [Pyr] as dynamical variables to provide more insight into cell responses of nitrogen signaling.

(3) Carbohydrate PTS catalyzes the uptake of carbohydrates [49], and it communicates with PTS ${ }^{\mathrm{Ntr}}$ through transfers of phosphoryl groups [62]. Therefore, including carbohydrate PTS into our model will help to understand environmental responses for both carbon and nitrogen shifts.

\section{Supplementary information}

Supplementary information accompanies this paper at https://doi.org/10.1186/s12859-020-03687-z.

Additional file 1: Calculations for ordinary differential equations.

Additional file 2: Phosphorylation of PTS ${ }^{N t r}$ is non-linearly dependent on the [PEP]:[Pyr] ratio in simulation.

\section{Abbreviations}

cdG: cyclic di-GMP, c-di-GMP; (p)ppGpp: alarmones guanosine tetraphosphate and guanosine pentaphosphate; PTS: phosphotransferase system; RSH: RelA-SpoT homolog; DGCs: diguanylate cyclases; PDEs: phosphodiesterases; GIn: glutamine; PEP: Phospho-enol-pyruvate; Pyr: Pyruvate; NDKs: nucleoside disphosphate kinases

\section{Acknowledgements}

Not applicable.

\section{About this supplement}

This article has been published as part of BMC Bioinformatics Volume 21 Supplement 14, 2020: Selected original articles from the Sixth International Workshop on Computational Network Biology: Modeling, Analysis, and Control (CNB-MAC 2019): bioinformatics. The full contents of the supplement are available online at https://bmcbioinformatics.biomedcentral. com/articles/supplements/volume-21-supplement-14.

\section{Authors' contributions}

BW conceptualized the project. CX and BW designed model equations and analyzed data. CX ran simulations, paramaterized the model, and wrote the first draft of the manuscript. CX, BW, and JT contributed to the text of the final draft of the manuscript. JT and YC provided biochemical expertise and computational technology, respectively. All author(s) read and approved the final manuscript.

\section{Funding}

This work was partially supported by the National Science Foundation (NSF) under awards CCF-1526666, MCB-1613741, and CCF-1909122. The funding sources played no role in the design of the study and collection, analysis, and interpretation of data and in writing the manuscript. Publication of this article is supported by NSF award CCF-1909122.

\section{Availability of data and materials}

The datasets generated and analysed during the current study are available at https://github.com/chunruixu/Secondmessenger-model-in-Caulobacter.git

Ethics approval and consent to participate

Not applicable.

\section{Consent for publication}

Not applicable.

\section{Competing interests}

The authors declare that they have no competing interests.

\section{Author details}

${ }^{1}$ Genetics, Bioinformatics, and Computational Biology, Virginia Tech, 24061 Blacksburg, VA, USA. ${ }^{2}$ Department of Biological Sciences, Virginia Tech, 24061 Blacksburg, VA, USA. ${ }^{3}$ Department of Computer Science, Virginia Tech, 24061 Blacksburg, VA, USA. 
Published: 30 September 2020

\section{References}

1. Shen X, Collier J, Dill D, Shapiro L, Horowitz M, McAdams HH. Architecture and inherent robustness of a bacterial cell-cycle control system. Proc Natl Acad Sci U S A. 2008;105(32):11340-5. https://www.ncbi.nIm.nih.gov/pmc/ articles/PMC2516238/.

2. Sánchez-Osorio I, Hernández-Martínez CA, Martínez-Antonio A. Modeling asymmetric cell division in Caulobacter crescentus using a boolean logic approach. In: Tassan JPandKubiak JZ, editor. Asymmetric Cell Division in Development, Differentiation and Cancer. Results and Problems in Cell Differentiation, vol. 61. Cham: Springer International Publishing; 2017. p. 1-21. https://doi.org/10.1007/978-3-319-53150-2_1.

3. Jenal U. The role of proteolysis in the Caulobacter crescentus cell cycle and development. Res Microbiol. 2009;160(9): 687-95. https://www.sciencedirect.com/science/article/pii/S0923250809001491.

4. Laub MT, Chen SL, Shapiro L, McAdams HH. Genes directly controlled by CtrA, a master regulator of the Caulobacter cell cycle. Proc Natl Acad Sci U S A. 2002;99(7):4632-7. https://www.ncbi.nlm.nih.gov/pmc/articles/PMC123699/.

5. Ryan KR, Judd EM, Shapiro L. The CtrA response regulator essential for Caulobacter crescentus cell-cycle progression requires a bipartite degradation signal for temporally controlled proteolysis. J Mol Biol. 2002;324(3):443-55. https:// doi.org/10.1016/S0022-2836(02)01042-2.

6. Smith SC, Joshi KK, Zik JJ, Trinh K, Kamajaya A, Chien P, Ryan KR. Cell cycle-dependent adaptor complex for ClpXP-mediated proteolysis directly integrates phosphorylation and second messenger signals. Proc Natl Acad Sci U S A. 2014;111(39):14229-34. https://www.pnas.org/content/111/39/14229.

7. Lori C, Ozaki S, Steiner S, Boehm R, Abel S, Dubey BN, Schirmer T, Hiller S, Jenal U. Cyclic di-GMP acts as a cell cycle oscillator to drive chromosome replication. Nature. 2015;523(7559):236-9. https://www.nature.com/articles/ nature14473.

8. Joshi KK, Bergé M, Radhakrishnan SK, Viollier PH, Chien P. An adaptor hierarchy regulates proteolysis during a bacterial cell cycle. Cell. 2015;163(2):419-31. https://www.ncbi.nlm.nih.gov/pmc/articles/PMC4600535/.

9. Chen YE, Tsokos CG, Biondi EG, Perchuk BS, Laub MT. Dynamics of two phosphorelays controlling cell cycle progression in Caulobacter crescentus. J Bacteriol. 2009;191(24):7417-29. https://jb.asm.org/content/191/24/7417.

10. Hallez R, Delaby M, Sanselicio S, Viollier PH. Hit the right spots: cell cycle control by phosphorylated guanosines in alphaproteobacteria. Nat Rev Microbiol. 2017;15(3):137-48. https://www.nature.com/articles/nrmicro.2016.183.

11. Kalia D, Merey G, Nakayama S, Zheng Y, Zhou J, Luo Y, Guo M, Roembke BT, Sintim HO. Nucleotide, C-di-GMP, c-di-AMP, cGMP, cAMP, (p)ppGpp signaling in bacteria and implications in pathogenesis. Chem Soc Rev. 2013;42(1): 305-41. https://pubs.rsc.org/en/content/articlelanding/2013/CS/C2CS35206K\#!divAbstract.

12. Jenal U, Malone J. Mechanisms of cyclic-di-GMP signaling in bacteria. Annu Rev Genet. 2006;40:385-407. https:// www.annualreviews.org/doi/pdf/10.1146/annurev.genet.40.110405.090423.

13. Schirmer T, Jenal U. Structural and mechanistic determinants of c-di-GMP signalling. Nat Rev Microbiol. 2009;7(10): 724-35. https://www.nature.com/articles/nrmicro2203.

14. Christen M, Christen B, Folcher M, Schauerte A, Jenal U. Identification and characterization of a cyclic di-GMP-specific phosphodiesterase and its allosteric control by GTP. J Biol Chem. 2005;280(35):30829-37. https:// www.jbc.org/content/280/35/30829.long.

15. Corrigan RM, Bellows LE, Wood A, Gründling A. ppgpp negatively impacts ribosome assembly affecting growth and antimicrobial tolerance in gram-positive bacteria. Proc Natl Acad Sci U S A. 2016;113(12):1710-9. https://doi.org/ 10.1073/pnas.1522179113.

16. Jagath J, Rodnina M, Wintermeyer W. Conformational changes in the bacterial SRP receptor Fts Y upon binding of guanine nucleotides and SRP. J Mol Biol. 2000;295(4):745-53. https://doi.org/10.1006/jmbi.1999.3427.

17. Ratnayake-Lecamwasam M, Serror P, Wong K, Sonenshein A. Bacillus subtilis CodY represses early-stationary-phase genes by sensing GTP levels. Genes Dev. 2001;15:1093-103. https://doi.org/10.1101/gad.874201.

18. Ronneau S, Petit K, De Bolle X, Hallez R. Phosphotransferase-dependent accumulation of (p)ppGpp in response to glutamine deprivation in Caulobacter crescentus. Nat Commun. 2016;7:11423. https://www.nature.com/articles/ ncomms11423.

19. Hauryliuk V, Atkinson GC, Murakami KS, Tenson T, Gerdes K. Recent functional insights into the role of (p)ppGpp in bacterial physiology. Nat Rev Microbiol. 2015;13(5):298-309. https://www.nature.com/articles/nrmicro3448.

20. Boutte C, Crosson S. The complex logic of stringent response regulation in Caulobacter crescentus: starvation signalling in an oligotrophic environment. Mol Microbiol. 2011;80(3):695-714. https://doi.org/10.1111/j.1365-2958. 2011.07602.x.

21. Kriel A, Bittner AN, Kim SH, Liu K, Tehranchi AK, Zou WY, Rendon S, Chen R, Tu BP, Wang JD. Direct regulation of GTP homeostasis by (p)ppGpp: a critical component of viability and stress resistance. Mol Cell. 2012;48(2):231-41. https://doi.org/10.1016/j.molcel.2012.08.009.

22. Anderson BW, Liu K, Wolak C, Dubiel K, She F, Satyshur KA, Keck JL, Wang JD. Evolution of (p)ppGpp-HPRT regulation through diversification of an allosteric oligomeric interaction. eLife. 2019;8:47534. https://doi.org/10. 7554/eLife.47534.

23. Pflüger-Grau K, Chavarría M, de Lorenzo V. The interplay of the Ell $A^{N \text { tr }}$ component of the nitrogen-related phosphotransferase system (PTSNtr) of Pseudomonas putida with pyruvate dehydrogenase. Biochim Biophys Acta-General Subj. 2011;1810(10):995-1005. https://www.sciencedirect.com/science/article/abs/pii/ S0304416511000055?via\%3Dihub.

24. Hogg T, Mechold U, Malke H, Cashel M, Hilgenfeld R. Conformational antagonism between opposing active sites in a bifunctional RelA/SpoT homolog modulates (p)ppGpp metabolism during the stringent response. Cell. 2004;117(3):415. https://pubmed.ncbi.nIm.nih.gov/15066282/.

25. Santillán M. On the Use of the Hill Functions in Mathematical Models of Gene Regulatory Networks. Math Model Nat Phenom. 2008;3(2):85-97. https://www.mmnp-journal.org/articles/mmnp/abs/2008/02/mmnp2008204/ mmnp2008204.html. 
26. Karelina TA, Ma H, Goryanin I, Demin OV. El of the phosphotransferase system of Escherichia coli: mathematical modeling approach to analysis of its kinetic properties. J Biophys. 2011;2011:579402. https://www.hindawi.com/ journals/jbp/2011/579402/.

27. Weigel N, Kukuruzinska MA, Nakazawa A, Waygood EB, Roseman S. Sugar transport by the bacterial phosphotransferase system. phosphoryl transfer reactions catalyzed by enzyme i of Salmonella typhimurium,. J Biol Chem. 1982:257(23):14477-91.

28. Pflüger K, de Lorenzo V. Evidence of In Vivo cross talk between the nitrogen-related and fructose-related branches of the carbohydrate phosphotransferase system of pseudomonas putida. J Bacteriol. 2008;190(9):3374-80. https:// doi.org/10.1128/JB.02002-07.

29. Ely B, Amarasinghe A, Bender RA. Ammonia Assimilation and Glutamate Formation in Caulobacter crescentus. J Bacteriol. 1978;133(1):225-30.

30. Patel HV, Vyas KA, Mattoo RL, Southworth M, Perler FB. Properties of the C-terinal domain of Enzyme I of the Escherichia coli phosphotransferase system. J Biol Chem. 2005;281(26):17579-87. https://doi.org/10.1074/jbc. M508966200.

31. Houot L, Chang S, Pickering BS, Absalon C, Watnick PI. The phosphoenolpyruvate phosphotransferase system regulates Vibrio cholerae biofilm formation through multiple independent pathways. J Bacteriol. 2010;192(12): 3055-67. https://jb.asm.org/content/192/12/3055.short.

32. Li YZ, Wang D, Feng XY, Jiao J, Chen WX, Tian CF. Genetic analysis reveals the essential role of nitrogen phosphotransferase system components in Sinorhizobium fredii CCBAU 45436 symbioses with Soybean and Pigeonpea Plants. Appl Environ Microbiol. 2016;82(4):1305-15. https://doi.org/10.1128/AEM.03454-15.

33. Wang J, Gilles ED, Lengeler JW, Jahreis K. Modeling of inducer exclusion and catabolite repression based on a pts-dependent sucrose and non-pts-dependent glycerol transport systems in Escherichia coli k-12 and its experimental verification. J Biotechnol. 2001;92(2):133-58. https://doi.org/10.1016/S0168-1656(01)00354-6. Biochemical Engineering: Trends and Potentials.

34. Postma PW, Lengeler JW, Jacobson GR. Phosphoenolpyruvate: Carbohydrate Phosphotransferase System of Bacteria. Microbiol Rev. 1993;57(3):543-94.

35. Mattoo RL, Waygood EB. Determination of the levels of HPr and enzyme I of the phosphoenolpyruvate-sugar phosphotransferase system in Escherichia coli and Salmonella typhimurium. Can J Biochem Cell Biol. 1983;61 (1): 29-37. https://pubmed.ncbi.nlm.nih.gov/6406017/.

36. Scholte BJ, Schuitema AR, Postma PW. Isolation of III Glc of the phosphoenolpyruvate-dependent glucose phosphotransferase system of Salmonella typhimurium. J Bacteriol. 1981;148(1):1257-264. https://www.ncbi.nlm.nih. gov/pmc/articles/PMC216188/.

37. Abel S, Bucher T, Nicollier M, Hug I, Kaever V, Wiesch PAZ, Jenal U. Bi-modal distribution of the second messenger c-di-GMP controls cell fate and asymmetry during the Caulobacter cell cycle. PLOS Genetics. 2013;9(9):1003744. https://journals.plos.org/plosgenetics/article?id=10.1371/journal.pgen.1003744.

38. Benoist C, Guérin C, Noirot P, Dervyn E. Constitutive stringent response restores viability of Bacillus subtilis lacking structural maintenance of chromosome protein. PLOS One. 2015;10(11):e0142308. https://journals.plos.org/ plosone/article?id=10.1371/journal.pone.0142308.

39. Boutte C, Henry JT, Crosson S. ppGpp and polyphosphate modulate cell cycle progression in Caulobacter crescentus. J Bacteriol. 2012;194(1):28-35. https://jb.asm.org/content/194/1/28.

40. Povolotsky TL, Hengge R. 'Life-style' control networks in Escherichia coli: Signaling by the second messenger c-di-GMP. J Biotechnol. 2012;160(1-2):10-16. https://www.sciencedirect.com/science/article/abs/pii/ S0168165611007024?via\%3Dihub.

41. Abel S, Chien P, Wassmann P, Schirmer T, Kaever V, Laub MT, Baker TA, Jenal U. Regulatory cohesion of cell cycle and cell differentiation through interlinked phosphorylation and second messenger networks. Mol Cell. 2011;43(4): 550-60. https://doi.org/10.1016/j.molcel.2011.07.018.

42. Goodwin RA, Gage DJ. Biochemical characterization of a nitrogen-type phosphotransferase system reveals that enzyme El ${ }^{\text {Ntr }}$ integrates carbon and nitrogen signaling in Sinorhizobium meliloti. J Bacteriol. 2014;196(10):1901-7. https://jb.asm.org/content/196/10/1901.

43. Joshi KK, Battle CM, Chien P. Polar localization hub protein PopZ restrains adaptor-dependent ClpXP proteolysis in Caulobacter crescentus. J Bacteriol. 2018;200(20):e00221-18. https://jb.asm.org/content/200/20/e00221-18.

44. Kharadi R, Castiblanco F, Waters M, Sundina W. Phosphodiesterase genes regulate amylovoran production, biofilm formation, and virulence in Erwinia amylovora. Appl Environ Microbiol. 2019;85(1):02233-18. https://doi.org/10. 1128/AEM.02233-18.

45. Purcell EB, Tamayo R. Cyclic diguanylate signaling in Gram-positive bacteria. FEMS Microbiol Rev. 2016;40(5):753-73. https://doi.org/10.1093/femsre/fuw013.

46. Abel S. Analysis of the c-di-GMP mediated cell fate determination in Caulobacter crescentus. PhD thesis, Universität Basel, Department of Biozentrum. 2009.

47. Commichau FM, Forchhammer K, Stülke J. Regulatory links between carbon and nitrogen metabolism. Curr Opin Microbiol. 2006;9(2):167-72. https://doi.org/10.1016/j.mib.2006.01.001. Cell Regulation / Edited by Werner Goebel and Stephen Lory.

48. Deutscher J, Aké F, Derkaoui M, Zébré A, Cao T, Bouraoui H, Kentache T, Mokhtari A, Milohanic E, Joyet P. The bacterial phosphoenolpyruvate: carbohydrate phosphotransferase system: regulation by protein phosphorylation and phosphorylation-dependent protein-protein interactions. Microbiol Mol Biol Rev. 2014;78(2):231-56. https://doi. org/10.1128/MMBR.00001-14.

49. Deutscher J, Francke C, Postma W. How phosphotransferase system-related protein phosphorylation regulates carbohydrate metabolism in bacteria. Microbiol Mol Biol Rev. 2006;70(4):939-1031. https://doi.org/10.1128/MMBR. 00024-06.

50. Kundig W, Roseman S. Sugar transport. i. isolation of a phosphotransferase system from Escherichia coli,. J Biol Chem. 1971;246(5):1393-406. 
51. Lee C, Park Y, Kim M, Kim Y, Park S, Peterkofsky A, Seok Y. Reciprocal regulation of the autophosphorylation of Enzyme Itr by Glutamine and $\alpha$-Ketoglutarate in Escherichia coli. Mol Microbio. 2013;88(3):473-85. https://doi.org/ 10.1111/mmi.12196.

52. Brauer MJ, Yuan J, Bennett BD, Lu W, Kimball E, Botstein D, Rabinowitz JD. Conservation of the metabolomic response to starvation acroos two divergent microbes. PNAS. 2006;103(51):19302-7. https://doi.org/10.1073/pnas. 0609508103.

53. Osanai T, Oikawa A, Shirai T, Kuwahara A, Lijima H, Tanaka K, Ikeuchi M, Kondo A, Saito K, Hirai MY. Capillary electrophoresis-mass spectrometry reveals the distribution of carbon metabolites during nitrogen starvation in Synechocystis sp. PCC 6803. Environ Microbiol. 2014;16(2):512-24. https://doi.org/10.1111/1462-2920.12170.

54. Yuan J, Doucette CD, Fowler WU, Feng XJ, Piazza M, Rabitz HA, Wingreen NS, Rabinowitz D.

Metabolomics-driven quantitative analysis of ammonia assimilation in E.coli. Mol Sys Biol. 2009;5(302):19302-7. https://doi.org/10.1038/msb.2009.60.

55. Hogema BM, Arents JC, Bader R, Eijkemans K, Yoshida H, Takahashi H, Alba H, Postma PW. Inducer exclusion in Escherichia coli by non-PTS substrates: the role of the PEP to pyruvate ratio in determining the phosphorylation state of enzyme IIA Glc. Mol Microbiol. 1998;30(3):487-98. https://onlinelibrary.wiley.com/doi/full/10.1046/j.1365-2958. 1998.01053.x.

56. Gorbatyuk B, Marczynski GT. Regulated degradation of chromosome replication proteins DnaA and CtrA in Caulobacter crescentus. Mol Microbiol. 2005;55(4):1233-45. https://doi.org/10.1111/j.1365-2958.2004.04459.x.

57. Flärdh K, Axberg T, Albertson N, Kjelleberg S. Stringent control during carbon starvation of marine Vibrio Sp. Strain S14: molecular cloning, nucleotide sequence, and deletion of the relA gene. J Bacteriol. 1994;176(19):5949-57. https://jb.asm.org/content/176/19/5949.

58. Bennett B, Kimball E, Gao M, Osterhout R, Van Dien S, Rabinowitz D. Absolute metabolite concentrations and implied enzyme active site occupancy in Escherichia coli. Nat Chem Biol. 2009;5(8):593-9.

59. Fischer M, Zimmerman TP, Short SA. A rapid method for the determination of Guanosine $5^{\prime}$-triphosphate-3'-diphosphate by high-performance liquid chromatography. Anal Biochem. 1982;121(1):135-9.

60. Gonzalez D, Collier J. Effects of (p)ppGpp on the progression of the cell cycle of Caulobacter crescentus. J Bacteriol. 2014;196(14):2514-25. https://jb.asm.org/content/196/14/2514.

61. Li S, Brazhnik P, Sobral B, Tyson JJ. Temporal controls of the asymmetric cell division cycle in Caulobacter crescentus. PLOS Comput Biol. 2009;5(8):e1000463. https://www.ncbi.nlm.nih.gov/pmc/articles/PMC2714070/.

62. Kremling A, Pflüger-Grau K, Chavarria M, Puchalka J, Santos V. Modeling and analysis of flux distributions in the two branches of the phosphotransferase system in Pseudomonas putida. BMC Syst Biol. 2012;6(149):149. https:// bmcsystbiol.biomedcentral.com/articles/10.1186/1752-0509-6-149.

\section{Publisher's Note}

Springer Nature remains neutral with regard to jurisdictional claims in published maps and institutional affiliations.

Ready to submit your research? Choose BMC and benefit from:

- fast, convenient online submission

- thorough peer review by experienced researchers in your field

- rapid publication on acceptance

- support for research data, including large and complex data types

- gold Open Access which fosters wider collaboration and increased citations

- maximum visibility for your research: over $100 \mathrm{M}$ website views per year

At BMC, research is always in progress.

Learn more biomedcentral.com/submissions 